\title{
Coronary artery bifurcation haemodynamics - comparison between phase contrast MRI and computational fluid dynamics
}

\author{
Susann Beier ${ }^{1}$, John Ormiston², Mark Webster², John Cater $^{3}$, Pau Medrano-Gracia ${ }^{1}$, Alistair Young ${ }^{1}$, Brett R Cowan ${ }^{1 *}$ \\ From 17th Annual SCMR Scientific Sessions \\ New Orleans, LA, USA. 16-19 January 2014
}

\section{Background}

Coronary atherosclerosis is common at vessel bifurcations. A quantitative approach to measuring blood velocity, vorticity and more complex flow features at bifurcations would enhance the understanding of the mechanisms of atheroma development, and potentially predict vessels at highest risk. The aim of this work was to validate 4D phase contrast (PC) magnetic resonance imaging flow measurements using a simplified arterial model of the left main coronary bifurcation against computational fluid dynamic (CFD) modelling.

\section{Methods}

A simplified left main to left anterior descending/circumflex bifurcation phantom was created from CT angiography data using $3 \mathrm{D}$ rapid prototyping. This was scaled up six-fold using the laws of dimensional scaling to an inlet diameter of $25 \mathrm{~mm}$ and connected to a pump to create a steady flow circuit in the MR scanner. Flow was measured using 4D PC MRI on a 3T Siemens Skyra (Erlangen, Germany). Custom software (MATLAB) was developed to convert the $\mathrm{PC}$ grey scale images to a structured data set with spacial, 3D velocity vector and time properties. The same geometry and conditions were then digitally modelled using CFD (ANSYS CFX 13.0 and Dell T5500, 64-bit
2.13 GHz six-core Intel Xeon with 12GB RAM) and the results exported to the same structured data set for comparison. The data was registered using a least squares 3D affine transformation and tri-linearly interpolated to create a co-registered $4 \mathrm{D}$ volume with more than 90 million data points which was then visualised as shown in Figure 1.

\section{Results}

The standard deviation of the differences between the PC and CFD data was less than $10 \%$. Regional flow features such as vortices were identified in the PC data, and were found to be subjectively similar to the corresponding features in the CFD data. Regions of PC artefact were identified using the CFD results, and were associated with lower spatial resolution and background eddy current effects.

\section{Conclusions}

PC MR flow measurements show good quantitative and structural flow similarity to CFD. CFD may be useful for the identification of regions of artefact in PC data and potentially provide a means of correction or regularisation.

\section{Funding}

Auckland Heart Group Charitable Trust. 


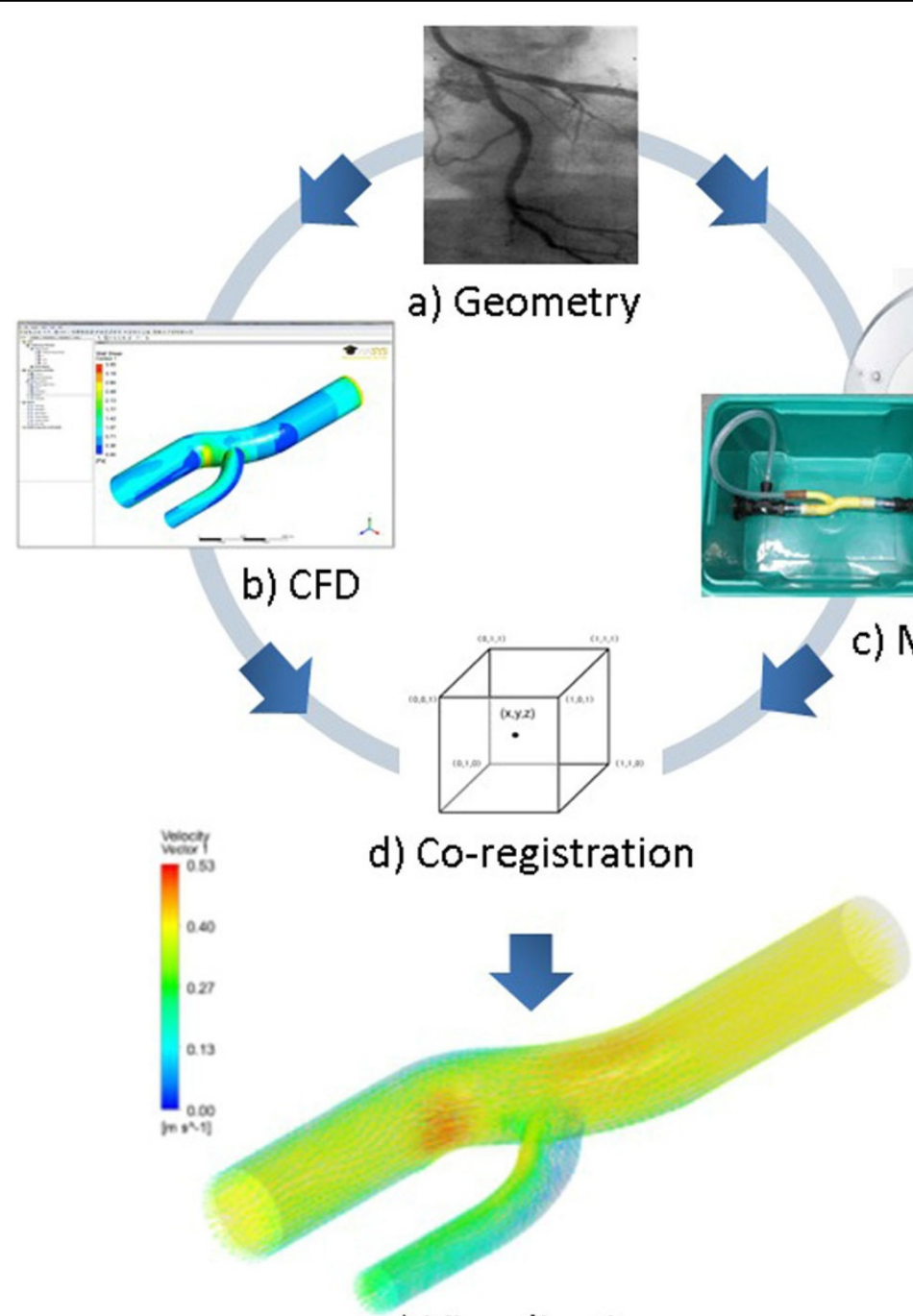

e) Visualisation

Figure 1 a) Simplified left main bifurcation geometry created from CT angiography data, b) CFD simulation, c) 4D PC MR flow measurements, d) co-registration, and e) visualisation and numerical comparison of the combined results.

\section{Authors' details}

'Auckland MRI Research Group, University of Auckland, Auckland, New Zealand. ${ }^{2}$ Department of Medicine, Auckland University, Auckland, New Zealand. ${ }^{3}$ Department of Engineering Science, University of Auckland, Auckland, New Zealand.

Published: 16 January 2014

doi:10.1186/1532-429X-16-S1-P224

Cite this article as: Beier et al:: Coronary artery bifurcation haemodynamics - comparison between phase contrast MRI and computational fluid dynamics. Journal of Cardiovascular Magnetic Resonance 2014 16(Suppl 1):P224.
Submit your next manuscript to BioMed Central and take full advantage of:

- Convenient online submission

- Thorough peer review

- No space constraints or color figure charges

- Immediate publication on acceptance

- Inclusion in PubMed, CAS, Scopus and Google Scholar

- Research which is freely available for redistribution

Submit your manuscript at www.biomedcentral.com/submit 